\title{
El constituyente profeta
}

\author{
Abraham Barrero Ortega \\ Profesor Titular de Derecho Constitucional \\ Universidad de Sevilla
}

Recibido: 17.05 .2012

Aceptado: 31.05 .2012

Resumen: La historiografía liberal española se ha sentido tradicionalmente incómoda con el hecho de que el primer constitucionalismo fuera tan intolerante en materia de conciencia y religión. El presente trabajo analiza las razones que llevaron al constituyente español de 1812 a proclamar la confesionalidad católica del Estado y prohibir el ejercicio de cualquier otro culto. Examina, asimismo, el influjo ejercido por el artículo 12 de la Constitución de 1812 a lo largo de la historia constitucional española.

Palabras clave: Constitución de Cádiz, confesionalidad católica, cuestión religiosa, libertad religiosa

Abstract: Spanish liberal historiography traditionally has felt uncomfortable with the fact that the first constitutionalism was so intolerant in religious matters. This paper analyzes the reasons why the Constitution of 1812 proclaimed the Catholic confessionalism and prohibited the exercise of any other cult and, on the other hand, the influence of Article 12 of the Constitution of 1812 in the Spanish constitutional history.

Key words: Constitution of Cadiz, Catholic confessionalism, religious question, religious freedom.

Sumario: I. Estado eclesiástico o Estado Iglesia.-II. Las razones de una "arriesgadísima profecía".- - III. Grado de acierto de la profecía constituyente.-IV. Pasado y futuro.

\section{ESTADO ECLESIÁSTICO O ESTADO IGLESIA}

Históricamente, la consolidación del Estado Constitucional ha estado ligada a la secularización, a la "mundanización" -sin sentido peyorativo alguno- de la religión y la sociedad, y más exactamente a la progresiva independencia del poder político respecto al poder eclesiástico. En tal sentido, secular equivale a laico, es decir, a no confesional. Con la secularización el Estado deja de ser confesional, se emancipa de cualquier tutela religiosa y se convierte en un Estado aconfesional. Recurriendo al ideal kantiano, podría decirse que la secularización es el cumplimiento de la "mayoría de edad" del Estado Constitucional. Éste "ya no necesita" la tutela de la religión, sino que puede decidir por sí mismo.

En verdad, Estado Constitucional y Estado laico son conceptos sinónimos, idénticos. La coherencia del Estado Constitucional exige un compromiso 
con la laicidad. El respeto a los derechos fundamentales demanda un Estado consecuente con la laicidad. Al Estado Constitucional le es exigible la independencia e imparcialidad de los poderes públicos en su trato con las diferentes confesiones religiosas. Es así como debe plasmarse la neutralidad del Estado en relación a las religiones, llevando a término lo que va implícito en la aconfesionalidad del mismo. Laicidad y pluralismo van juntos y el respeto de ambos forma parte del "tipo Estado Constitucional"1.

Si la libertad religiosa ha sido tan importante en el proceso de imposición primero y de afirmación después del Estado Constitucional "ha sido por su carácter problemático durante los siglos que van de la Reforma y Contrarreforma a las revoluciones americana y francesa"'2. La libertad religiosa ha sido crucial para el transcurso del Estado Constitucional por su reconocimiento/no reconocimiento durante ese período. La lucha por su reconocimiento "ha sido el motor que acabaría desembocando en el Estado Constitucional"3. Durante la primera fase de afirmación del Estado Constitucional en el continente europeo, la libertad religiosa continuó siendo un problema y un obstáculo significativo en el proceso de afirmación del Estado. En unos países más y en otros menos. En España, entre los países europeos, de los que más.

Los Reyes católicos construyeron la unidad nacional de España sobre la unidad religiosa y sobre la pureza de sangre. Las expulsiones de los judíos y de los moriscos, la guerra contra el reino de Granada y la persecución de todos los herejes, protestantes y heterodoxos se enmarcan en ese propósito de unificación nacional. El que ambas unidades se consiguieran por los mismos años no fue en modo alguno coincidencia. La unidad religiosa reforzó la unidad nacional, de forma similar a como ésta se convirtió en garantía de aquélla. La unidad religiosa suponía el elemento constitutivo de la unidad nacional. La lucha por la religión y por la Nación se identificaron. El catolicismo se presentó como un aspecto irrenunciable de la identidad colectiva, como parte de la esencia y tradición propiamente españolas, implicando todo ello el combate contra el luteranismo (España, "martillo de herejes", "luz de Trento", "espada de Roma"). En España, la Contrarreforma desempeñó el papel moldeador de la identidad colectiva que en otros países correspondió a la Reforma protestante. Ser español significaba ser católico ${ }^{4}$.

Fueron demasiados siglos persiguiendo, censurando, desterrando, excomulgando, imponiendo cánones de vida y creencias. En ese tiempo, se hizo más fácil, en España, creer que pensar, porque la religiosidad no se podía in-

${ }^{1}$ Peter Häberle, Libertad, igualdad y fraternidad. 1789 como historia, actualidad y futuro del Estado Constitucional, Minima Trotta, Madrid, 1998, pp. 45 y ss.

2 Javier Pérez Royo, Curso de Derecho Constitucional, Marcial Pons, Madrid, 1999, pp. 290.

${ }^{3}$ Ibid.

${ }^{4}$ José Álvarez Junco, Mater dolorosa: la idea de España en el siglo XIX, Taurus, Madrid, 2001, pp. 303-496. 
dividualizar, sino que debía expresarse a través de las plantillas de la religión establecida, la única y verdadera. Muy pocos se atrevieron a criticar la intolerancia, la conversión forzada y la limpieza en la sangre, el que -en palabras de Alonso Virués, humanista y obispo- "se usasen las cadenas y el hacha para cambiar la disposición del alma".

Por aquel entonces, en asuntos de religión, no se reclamaba convicción o acuerdo, bastaba la simple adhesión. El Estado y la Iglesia católica se repartían la tarea del mutuo fortalecimiento, a veces rozando el modelo de integración, lo que Ortega llamaba el Estado eclesiástico o Fernando de los Rios el Estado Iglesia.

Además, la unidad religiosa favorecía la estabilidad social. La Inquisición actuaba más como un instrumento de policía política destinado a evitar la introducción de ideas novedosas o rupturistas. Y al ir desapareciendo los enemigos tradicionales de la ortodoxia católica, como los moriscos, los protestantes o los cripto-judíos, el Santo Oficio fijó su atención en otros adversarios como los revolucionarios y los liberales. La Inquisición debería percibirse como un reflejo de los intereses de clases más que de los intereses de la religión. En tanto que contribuyó al inmovilismo de una sociedad determinada y puso barreras a novedades entendidas como peligrosas, fue un factor conservador del estado de cosas dominante y, por lo mismo, favorecedor de los estamentos privilegiados 5 .

Vino después el siglo XIX, el de los grandes cambios -anunciados y gestados en el pasado-, y con él la revolución burguesa, el Estado liberal y la Constitución como técnica específica de organización del poder político con una inequívoca finalidad de garantía, código político que divide los poderes del Estado y declara derechos y libertades de los ciudadanos.

Y entre esos derechos "naturales", "imprescriptibles" e "inalienables", la libertad de conciencia religiosa. La incardinación formal de la libertad de conciencia religiosa en un catálogo general de derechos del hombre tendrá lugar sólo después de que el constitucionalismo liberal crease a tal efecto la cobertura normativa idónea con la que actuar el fundamento argumental secularizado ideado por el racionalismo ilustrado -Milton, Spinoza, Bayle, Locke o Thomasius $-{ }^{6}$. La conciencia religiosa se concibe como objeto de un derecho; la libertad religiosa es exigible como derecho. Cada cual puede decidir por sí y para sí mismo su destino religioso. La libertad religiosa pasa así a integrarse en el derecho que, en virtud de su dignidad racional, corresponde al hombre a mantener y profesar las creencias que libremente asuma. El individuo ha de poder asumir aquellas doctrinas que se impongan como verdaderas

${ }^{5}$ Henry Kamen, Nacimiento y desarrollo de la tolerancia en la Europa moderna, Alianza, Madrid, 1987, pp. 140-153.

${ }^{6}$ Abraham Barrero Ortega, "Origen y actuación de la libertad religiosa", Derechos y libertades, 9, 2000, pp. 206 y ss. 
desde el convencimiento racional de la conciencia. Como Bartolomé Clavero ha escrito en referencia al proceso constituyente americano, la religión "no es law" o deber objetivo, "sino right" o derecho subjetivo ${ }^{7}$. Un derecho innato, en el sentido de que deriva de una ley natural previa a todo poder político y motivo de la ley positiva.

El constituyente americano de 1787 apenas hizo mención a las relaciones entre el gobierno y la religión, extendiendo a esta parcela el silencio que guarda respecto al conjunto de libertades civiles. La única excepción la constituye la disposición del artículo 6, donde se recoge la prohibición de exigir profesión de fe alguna para obtener empleo o cargo público. Sin embargo, ese silencio quedaría muy pronto integrado con la primera de las diez enmiendas a la Constitución de los Estados Unidos, propuesta por el Congreso en su primera legislatura y ratificada en 1791, que prohíbe que el poder legislativo haga ley alguna con respecto a la adopción de una religión (establishment clause) o haga ley alguna que prohíba la práctica religiosa (free exercise clause). La free exercise clause veda cualquier grado de compulsión directa o indirecta sobre las creencias. La establishment clause refleja el ideal de Jefferson y Madison, para quienes las funciones del gobierno y de la religión se desarrollarían de un modo más próspero si el uno permaneciese independiente de la otra.

En la misma dirección, el artículo 10 de la Declaración de derechos del hombre y del ciudadano de 1789 establece que "ningún hombre debe ser molestado por razón de sus opiniones, ni aun por sus ideas religiosas, siempre que al manifestarlas no se causen trastornos del orden público establecido por la ley", de modo que se dejan sin efecto las previsiones del Edicto de Tolerancia de 1787, desplazadas por lo que, en el curso de las deliberaciones parlamentarias, el marqués de Mirabeau denominase la "plena libertad de pensamiento" . Poco después, la Constitución de 1791 garantizaría, en su capítulo de disposiciones fundamentales, la libertad de todo hombre de "ejercer el culto religioso al que pertenece".

Cuando Locke, en su Carta sobre la tolerancia (1689), afirma que los derechos del hombre son ajenos a la religión, piensa, sin duda, en ese proceso de secularización y en esa lucha por la libertad religiosa que alcanza desde el siglo XVI al XVIII. Si los textos fundacionales del Estado Constitucional tratan de convertir la libertad genérica en autodeterminación que se expresa en derechos concretos vinculados a la dignidad humana, ninguna relación entre poderes, ningún "compromiso religioso" -en expresión del constituyente revolucionario francés de 1791- puede obstaculizar el reconocimiento de la libertad de conciencia lato sensu.

\footnotetext{
${ }^{7}$ Bartolomé Clavero Salvador, Los derechos y los jueces, Civitas, Madrid, 1988, p. 30.

${ }^{8}$ Citado según Stéphane Rials, La Déclaration des droits de l'homme et du citoyen, Hachette, París, 1988, p. 245.
} 


\section{LAS RAZONES DE UNA "ARRIESGADÍSIMA PROFECÍA"}

¿Qué sucede entre nosotros por esas mismas fechas con la libertad de conciencia y la actitud del poder público ante las Iglesias o confesiones? Que nadie se engañe. El planteamiento que en España subsiste es el del binomio antitético entre verdad religiosa y libertad de conciencia. Durante gran parte del siglo XIX, en el plano constitucional del Estado, no cabe la libertad en un terreno que continúa abandonado al poder una Iglesia establecida. Siglos de Inquisición y de persecución de la herejía hicieron de nuestra condición colectiva, de nuestra Constitución social-material, una red de intransigencia, fanatismo e intolerancia. El pensamiento de Pierre Bayle en su Comentario filosófico (1686), de Locke en su Carta sobre la Tolerancia, de Voltaire en su Tratado sobre la tolerancia (1767) o de Stuart Mill en Sobre la libertad (1859) no se integró en la cultura política española. Eran disidentes o heterodoxos marginales quienes lo sostenían. La unidad religiosa como dogma o statu quo.

En 1818, el entonces obispo de Ceuta fray Rafael Vélez, uno de los principales doctrinarios del absolutismo, defendía en su Apología del Altar y del Trono (1818) la unidad religiosa como antídoto frente a la inestabilidad política. Las convulsiones - decía- que de medio siglo a esta parte han asolado Europa han tenido su origen en las reformas de los gobiernos en materia de conciencia y religión. Si los reinos católicos -Italia, Francia o Alemania- no hubieran dado acogida "a los planes de reforma eclesiástica y a las nuevas doctrinas sobre la religión, sus pueblos hubieran seguido como antes unidos a sus obispos, sus curas y ministros de la Iglesia, y necesariamente adheridos al trono". Vélez adopta frente a los innovadores o reformistas el punto de vista español y católico y los presenta como vendidos a la impiedad.

Otro texto contemporáneo a la Apología del Altar y del Trono es de 1812 y dice así:

"La religión de la Nación española es y será perpetuamente la católica, apostólica, romana, única verdadera. La Nación la protege por leyes sabias y justas y prohíbe el ejercicio de cualquier otra".

Aparte de su "arriesgadísima profecía", lo más llamativo de tan contundente e intolerante párrafo es que pertenece a la Constitución de 1812, símbolo de nuestro constitucionalismo decimonónico y bandera del liberalismo español durante décadas frente a las posiciones absolutistas. Si en algunos aspectos triunfó el liberalismo, en materia religiosa se impuso la tradición al recogerse en el artículo 12 una de las fórmulas más intransigentes e intolerantes de la

\footnotetext{
${ }^{9}$ Francisco Tomás y Valiente, Recensión del libro de L. Martín-Retortillo Libertad religiosa y orden público. Un estudio de jurisprudencia (Madrid, 1970), en Francisco Tomás y Valiente, Obras completas, tomo VI, Centro de Estudios Políticos y Constitucionales, Madrid, 1997, p. 5039.
} 
historia constitucional española. Una fórmula de "confesionalidad extrema junto a la negación absoluta de la libertad religiosa"10.

La historiografía liberal española se ha sentido tradicionalmente incómoda con el hecho de que el primer constitucionalismo fuera tan intolerante, calificando el artículo 12 de pura concesión a las condiciones de la época hecha a desgana y bajo presión por unos liberales para los que la situación debida no era otra cosa que la libertad de conciencia. La mayor prueba de esta posición es un texto de Argüelles contenido en La reforma constitucional $(1835)^{11}$ que, en mi opinión, no ha de interpretarse sino en el contexto de quien, años más tarde, asumiendo que la experiencia liberal gaditana no fue un éxito pleno, realizaba un ejercicio de autocrítica. Sin olvidar la actitud de los propios liberales cuando, a partir de 1833, con la Iglesia apoyando mayoritariamente al bando carlista, con la desamortización en marcha y el poder político en sus manos, no obraron de manera muy distinta. Otras razones explican la decidida apuesta del constituyente gaditano a favor de la catolicidad de la Nación; algo había en "el mapa genético"12 del primer liberalismo español que justifica el sentido y alcance del artículo 12.

Para empezar, la confesionalidad sociológica de la Nación era no sólo un hecho indiscutible, sino hasta una ventajosa realidad. Valía la pena abrir nuevos frentes de distanciamiento respecto a los absolutistas y quienes les apoyaban por muchas razones, pero no por una cuestión meramente teórica, sin ninguna relevancia práctica. La disidencia religiosa se consideraba sólo especulativamente, de forma imaginaria, sin fundamento. Si la defensa ilustrada de la libertad religiosa tuvo mucho de pragmatismo, allí donde no existe conflicto religioso no hay por qué traicionar la tradición. Españolidad y catolicidad eran lo mismo. Se diría que el constituyente gaditano hizo suya la máxima de Bodino: "cuando la religión es aceptada por común consentimiento, no debe tolerarse que se discuta, porque de la discusión se pasa a la duda (...). Es de suma importancia que cosa tan sagrada (...) no sea menospreciada ni puesta en duda mediante disputas, pues de ello depende la ruina de la República"13.

Por otro lado, para nuestros primeros liberales, la laicidad es una fábula producida por el reformismo agnóstico y la Nación, en cuanto humanidad del

${ }^{10}$ Alberto de la Hera Pérez Cuesta, "Confesionalidad y libertad religiosa en el Derecho Constitucional español (1808-1975)", en Abraham Barrero Ortega y Manuel Terol Becerra, La libertad religiosa en el Estado social, Tirant Lo Blanch, Valencia, 2009, p. 66.

${ }^{11}$ Según Argüelles, para consagrar la libertad religiosa "hubiera sido necesario luchar frente a frente con toda la violencia y furia teológica del clero, cuyos efectos demasiado experimentados estaban ya así dentro como fuera de las Cortes" - citado según Agustín de Argüelles, La reforma constitucional, Iter, Madrid, 1970, pp. 262-263-.

12 José María Portillo Valdés, "De la Monarquía Católica a la Nación de los católicos", Historia y Política, 17, 2007, pp. 17-35.

${ }^{13}$ Jean Bodino, Los seis libros de la República, IV, Universidad de Venezuela, Caracas, 1965, p. 302. 
hombre, debía contener en sí la religión, ocuparse de la fe del pueblo y favorecer el culto religioso nacional. Retomando la cita anterior de Bartolomé Clavero, cabría afirmar que en Cádiz la religión es más deber objetivo o presupuesto político de la Nación que contenido de un derecho subjetivo. Muñoz Torrero, presidente de la Comisión constitucional, lo expresaría abiertamente: “(...) la Comisión jamás ha dudado que a la Nación le toca defender y proteger la religión, puesto que es el principal deber a que está obligado todo ciudadano" 14 .

La religión es sencillamente ley fundamental de la Monarquía ${ }^{15}$. O, ahora, más exactamente, ley fundamental de la Nación, que se compromete a protegerla por leyes sabias y justas y a prohibir cualquier otro culto. El artículo 12 encierra "un giro que conduce de la Monarquía católica a la Nación católica" ${ }^{16}$. La vinculación de Nación y religión es coherente con la idea de la soberanía de la Nación y de su primacía en el nuevo orden constitucional. Mencionar a la Nación en vez de a la Monarquía conllevaba de manera indirecta dar entrada a la soberanía nacional.

Como quiera que sea, al margen del sujeto al que le competiese proteger la fe del pueblo, lo decisivo, insisto, es que la religión se contempla -en palabras del obispo y diputado Inguanzo Rivero- como "ley primera y antigua fundamental" 17 , como un principio o fundamento de nuestra Constitución tradicional española, de suerte que está por encima de cualquier decisión popular, incluyendo al legislador constituyente. Una de esas leyes fundamentales que no se pueden poner en tela de juicio porque el sistema descansa en la existencia de ellas.

Si los liberales de Cádiz hubiesen hablado de libertad de pensamiento y de su expresión como libertad de todos y de todo pensamiento se habrían situado en el terreno de los derechos naturales de todo hombre como fundamento del sistema y como límite del poder. Pero no fue así. No hay en Cádiz derechos básicos o prepolíticos. Les preceden unos valores, unas instituciones, unas leyes fundamentales. Una Nación, unas Cortes, una Monarquía y, como refleja el artículo 12, una Iglesia establecida, "un establishment of religion como el que en Norteamérica fuese proscrito como primera y elemental diligencia del bill of rights federal" 18 . Otras realidades son verdaderamente fundamentales. Prevalecen sobre la libertad y los derechos.

${ }^{14}$ Diario de Sesiones, 30 de agosto de 1811, p. 1729.

${ }^{15}$ En el sentido de Francisco Tomás y Valiente, "Génesis de la Constitución de 1812. De muchas leyes fundamentales a una sola Constitución", Anuario de Historia del Derecho español, 65, 1995, pp. 13-126, y Santos Coronas González, "Las Leyes fundamentales del Antiguo Régimen. (Notas sobre la Constitución histórica española)", Anuario de Historia del Derecho español, 65, 1995, pp. 19-66.

${ }^{16}$ José María Portillo Valdés, op. cit., p. 35.

${ }^{17}$ Diario de Sesiones, 2 de septiembre de 1811, pp. 1745-1746.

${ }^{18}$ Bartolomé Clavero Salvador, op. cit., p. 62. 
Nótese, en tal sentido, que el artículo 4 de la Constitución de 1812 reconoce la libertad civil, la propiedad y "los demás derechos legítimos de todos los individuos" que componen la Nación. No se habla de derechos del hombre, sino de derechos de los individuos que integran la Nación, esto es, los derechos de los españoles. La libertad que se garantiza es la libertad civil, conforme a la ley, y los derechos, lejos de ser naturales, imprescriptibles o inderogables, son legítimos. La discrepancia respecto a la concepción francesa y americana es patente: lo legítimo es una categoría jurídica, política y social, por lo que mal pueden estos derechos ser anteriores y superiores a una comunidad política que ya está constituida. Los españoles son titulares de derechos, pero los disfrutan en su condición de tales, por su pertenencia a la Nación y, en todo caso, de acuerdo con sus leyes fundamentales. Los derechos legítimos se reconocen en el seno de la Nación, de modo que las leyes sabias y justas a las que alude el artículo 4 (las mismas leyes sabias y justas a las que el artículo 12 encomienda la protección de la religión oficial) pueden condicionar o sacrificar su reconocimiento atendiendo a su Constitución histórica o, lo que es lo mismo, a sus leyes fundamentales. La Nación no es la unión de los españoles que la forman, sino éstos sumados con los de siglos pasados. La libertad está limitada por lo que la Nación debe a su pasado. Se impone la tradición en cuanto conjunto de costumbres y normas heredadas del pasado. Más que de derechos individuales, puede hablarse en Cádiz de derechos sociales. Los derechos no son anteriores a la sociedad; son consecuencia de la misma. No se conciben como premisas de un orden a constituir. Se consideran resultantes de un orden constituido.

Es muy revelador que tanto en la Ley sobre responsabilidades de los infractores de la Constitución, de 18 de abril de 1821, como en el Código Penal, de 8 de junio de 1822, las conductas contrarias a la religión católica se contemplasen como delitos contra una de las bases fundamentales de la Nación. Todos los supuestos de traición contemplados en una y otra ley $-\mathrm{y}$ entre ellos la disidencia religiosa- representaban atentados contra los presupuestos políticos o leyes fundamentales del restaurado Estado liberal: la monarquía hereditaria, la división de poderes, las Cortes y la religión católica. El disidente religioso es reo de Estado y la herejía o la apostasía un delito político ${ }^{19}$.

Ni siquiera la supresión de la Inquisición en febrero de 1813 modificó sustancialmente este statu quo, no ya porque la confesionalidad subsistía en la Constitución, sino porque el propio decreto de abolición insistía en su artículo I.1 en que la religión católica debía ser preservada. La supresión del Santo Oficio supuso la eliminación de una incómoda jurisdicción eclesiástica especial, para que resurgiesen las competencias de los tribunales eclesiásticos ordinarios para conocer las causas de fe, ante las cuales cualquier español

${ }^{19}$ Alicia Fiestas Loza, Los delitos politicos (1808-1936), Gráficas Cervantes, Salamanca, 1977, pp. 60 y ss. 
tenía "acción para acusar del delito de herejía". Y todo ello sin perjuicio de que el Rey materializase aquella protección con medidas que evitasen la introducción en España "de libros y escritos prohibidos o que sean contrarios a la Religión".

Aquí radica la lógica por la que nuestros primeros liberales pudieron negar la libertad religiosa sin incurrir aparentemente en contradicción. La asociación entre Nación y religión se aceptó de manera natural en tanto "seña de identidad supuesta y superpuesta al proceso mismo de creación constitucional"20. Hay un código esencial católico que delimita el alcance de la libertad.

Un signo necesario de españolidad y de ciudadanía española que, por lo demás, impregna todo el texto constitucional. La Constitución se promulga "en nombre de Dios todopoderoso, Padre, Hijo y Espíritu Santo (...)"; el municipio, a efectos electorales, adopta la parroquia como circunscripción electoral (art. 35); antes de la votación en las elecciones se debe celebrar una misa (art. 48) y, tras la proclamación de los candidatos electos, se cantará un Te Deum (art. 58); cada año se hace jurar a los diputados "defender y conservar la religión católica, apostólica, romana, sin admitir otra alguna en el reino" (art. 117); las leyes se promulgan ordenándose su cumplimiento a todas las autoridades civiles, militares y eclesiásticas (art. 155); el Rey tiene el tratamiento de Majestad Católica (art. 169) y presta juramento ante las Cortes bajo una fórmula que alude al carácter católico de la institución (art. 173); el Rey ostenta el derecho de presentación de obispos (art. 171. $6^{\mathrm{a}}$ ); cuatro consejeros de Estado son eclesiásticos (art. 232); perdura el fuero eclesiástico (art. 249); y en las escuelas de primeras letras se enseña a los niños a leer, escribir y contar y el catecismo de la religión católica (art. 366). Como se ha dicho, la Constitución de Cádiz era "integralmente confesional"

\section{GRADO DE ACIERTO DE LA PROFECÍA CONSTITUYENTE}

La confesionalidad católica del Estado asumida por la Constitución de 1812 y la prohibición contra cualquier otra práctica religiosa marcaría el futuro de nuestro Estado liberal en este terreno. La idea de la separación entre el poder político y la o las Iglesias, así como la libertad de conciencia en materia religión, fueron desconocidas por las Constituciones doctrinarias de 1837,1845 y 1876 , provocando con ello la crisis de todo el sistema constitucional del Estado. Basta, en todo caso, leer atentamente el artículo 11 de estos tres textos constitucionales para caer en la cuenta, sin excesiva dificultad, de que la confesionalidad allí consagrada tiene un alcance y una significación diversa a la de 1812.

Apartándose, en efecto, del precedente gaditano, y aunque a primera vista no sea tan evidente, las Constituciones de 1837, 1845 y 1876 mantuvieron,

\footnotetext{
${ }^{20}$ José María Portillo Valdés, op. cit., p. 19.

${ }^{21}$ José María Portillo Valdés, op. cit., p. 26.
} 
en unos términos menos rotundos, la confesionalidad sustancial del Estado, pero compatible con la tolerancia de cultos, esto es, el reconocimiento legal (expreso o tácito) del derecho a la libre profesión de su fe a los fieles de religiones distintas a la oficial en un ámbito estrictamente privado. El Estado eclesiástico o Estado Iglesia, como concesión frente al error, autoriza la práctica privada del culto. La tolerancia de cultos es un concepto negativo y relativo. Es en el caso límite, aunque frecuente en nuestra historia constitucional, de la imposición coactiva por parte de un grupo de sus propias creencias religiosas a los que disienten de ellas cuando la pretensión de tolerancia cobra sentido, traduciéndose entonces en el reconocimiento de cierta inmunidad para los que profesan religiones distintas de la establecida oficialmente. En realidad, las más tempranas afirmaciones de tolerancia (1837 y 1845) sólo significaron la exclusión de la violencia del ámbito religioso, sin que ello supusiese el reconocimiento de la plena libertad de conciencia. Los textos constitucionales más representativos del doctrinarismo político español consagraron la tolerancia de cultos en las coordenadas de una sociedad donde existía una Iglesia de Estado que ostentaba, en principio, la posibilidad de imponer coactivamente, por sí misma o mediante el gobierno secular, sus dogmas, pero que, por pragmatismo, renunciaba a ello ${ }^{22}$.

En cambio, la auténtica libertad religiosa implica el reconocimiento de un ámbito de inmunidad personal irreductible en orden a la realización del acto de fe y de cuantas otras expresiones individuales o colectivas éste lleva aparejado, generándose así un deber de abstención o de no interferencia que vincula tanto a los poderes públicos como a los demás sujetos privados. Dicha libertad presupone la posibilidad de que cada individuo persiga libremente sus fines espirituales superiores, reclamando, consecuentemente, las siguientes condiciones: a) el reconocimiento de autonomía individual para la elección y manifestación de las creencias; b) la autonomía del grupo religioso en la realización de sus fines; y) la igualdad de esos individuos y grupos ante la autoridad política.

La lógica jurídica del liberalismo doctrinario para negar la plena libertad religiosa es semejante a la del constituyente de 1812. Los derechos individuales deben figurar en la Constitución enunciados en términos genéricos y con cláusula remisiva a leyes futuras que los desarrollen y limiten, sin que hasta que se produzca esa implementación sean más que meras declaraciones dotadas de valor político, pero no de fuerza jurídicamente vinculante. Los derechos quedan así degradados y trivializados. No son fundamentales, no son la esencia de la estructura jurídico política que diseña la Constitución, núcleo básico e irrenunciable del estatuto jurídico del individuo. No se reconocen, sólo se conceden. Y es que, en realidad, lo que se quiere garantizar no es la

${ }^{22}$ Francisco Tomás y Valiente, A orillas del Estado (Cap. IX: Sobre la tolerancia), Taurus, Madrid, 1996, pp. 221 y ss.

${ }^{23}$ Diario de Sesiones, 27 de marzo de 1876, p. 2. 
autodeterminación completa del individuo, su libertad, sino un concreto orden socio-político. El Estado reviste una forma histórica dada: la propia de la Nación española según su historia. Se invoca así la existencia de una Constitución histórica de España, de un fondo común de la Constitución monárquica, como vínculos a respetar a la hora de elaborar la Constitución escrita, lo que, en último extremo, significa que la voluntad del constituyente se encuentra supeditada a la fidelidad a ciertos elementos tradicionales de la Nación. En nuestra Constitución interna o no escrita existen principios históricos, "atributos esenciales" en palabras de Cánovas ${ }^{23}$, dotados de un valor absoluto en el sentido de que se imponen con la sola legitimidad de su existencia histórica. Y dentro de este planteamiento historicista que exige lealtades conservadoras al constituyente, también la Iglesia católica se sitúa por encima del orden constitucional. Lo español, desde siempre, había sido, y debía seguir siendo, la defensa de la fe católica por parte del poder político.

En otro orden de consideraciones, solía pensarse, no sin sentido, que la libertad de conciencia iba unida a la democracia, a un nuevo espíritu público que reivindicaba derechos y libertades donde en la sociedad española sólo había existido opresión y defensa de la ortodoxia católica. La vinculación entre conservadurismo político y conservadurismo religioso es clara. Para Balmes, el catolicismo era el fundamento de la Nación española.

Por lo demás, la aplicación del principio de mera tolerancia al terreno de las creencias religiosas no significó -reitero- un igual trato ante la ley de los diversos grupos confesionales, una libertad igualitaria cuyo ejercicio no generase discriminaciones. Se diría más bien que, bajo la vigencia de las Constituciones de 1837, 1845 y 1876, y sobre todo tras la firma del Concordato de 1851, la Iglesia es copartícipe de un sui generis poder constituyente vinculado a la tradición. Lo más importante del Concordato de 1851 fue el haber servido de punto de partida para el desarrollo de toda una serie de principios en él contenidos, superponiéndose incluso a la Constitución y afianzando la vinculación institucional de la Iglesia con el Estado.

Sin desconocer que a lo largo del siglo XIX se planteó en la sociedad española un cierto conflicto religioso - polarizado en torno a la Inquisición y a la desamortización eclesiástica-, bajo la vigencia de las Constituciones de 1837, 1845 y 1876 los gobiernos liberales mantuvieron tres principios ${ }^{24}$ : a) confesionalidad; b) exclusión (por vía prohibitiva expresa o ex silentio) de otros cultos no católicos; y c) dotación de culto y clero católicos -no se olvide que andaba pendiente la cuestión de la desamortización y que esa obligación de sufragar los gastos de culto y clero quedó reconocida tanto en la Ley de Mendizábal de 29 de julio de 1837 como en el Concordato de 1851-. La continuidad es manifiesta. El modelo de integración Estado Iglesia quedó certificado en la Constitución y en otros textos legales. El Estado y la Iglesia

\footnotetext{
${ }^{24}$ Alberto de la Hera Pérez Cuesta, op. cit., pp. 67-88.
} 
católica se aliaron profundamente, formando un bloque homogéneo. La defensa de la catolicidad de España y la confesionalidad del Estado representaron la formulación más completa de la identidad católica nacional.

En cambio, las Constituciones de 1869 y 1931 significaron cambios ostensibles frente a esta tradición. Los derechos son el fundamento y la meta del poder político, no una concesión otorgada con desconfianza y en atención a criterios de oportunidad. Por vez primera en la historia de nuestro constitucionalismo aparecen expresiones como libertades públicas o derechos fundamentales. Aluden a una realidad jurídica indisponible para los poderes públicos y, en especial, para el legislador. No se prohíbe que las Cortes legislen sobre ellos, pero se deja constancia de que las Constituciones no dejan espacios muertos, por silencio legal, que luego pueden ser rellenados por una acción legislativa limitadora. Además, los derechos se reconocen en la Constitución, que no es, como en la concepción doctrinaria, una ley como otra cualquiera, sino una norma jurídica de rango superior y de carácter vinculante. La lex legum. Las Constituciones de 1869 y 1931 muestran una sincera adhesión al principio de los derechos fundamentales en los que, por el contrario, no parecía creer el constituyente de 1812, 1837, 1845 y 1876. Los derechos son el principio o cimiento sobre el que se apoya todo el sistema político, recobrando así la Constitución su función original.

Como no podía ser de otra forma, y pese a alguna contradicción, este replanteamiento también aprovechará a los derechos de la conciencia en general y a la libertad religiosa en particular. En un Estado constitucional de derechos, y derechos fundamentales, no hay lugar para la intolerancia ni para la mera tolerancia. La libertad de conciencia es un prius frente a las relaciones entre el Estado y las Iglesias. La sociedad no puede coaccionar a los individuos contra su voluntad excepto en defensa propia. La única finalidad por la cual se pueden limitar las manifestaciones de la conciencia es la de evitar que perjudiquen a los demás. Ya no es posible justificar la restricción de las manifestaciones más importantes de la libertad de pensamiento con el simplismo historicista de Inguanzo o con los argumentos doctrinarios de Balmes, Donoso o Cánovas.

El constituyente de 1869 eludió cualquier pronunciamiento respecto a la confesionalidad o laicismo del Estado; por otra parte, permitía el ejercicio público y privado de cualquier culto y, finalmente, asumía la obligación de mantener el culto y clero católicos, como venía proclamándose desde 1837. Si bien es cierto que la Iglesia católica continuó recibiendo un trato privilegiado, no es menos cierto que el artículo 21 de la Constitución de 1869 significó un paso cualitativo importante hacia el distanciamiento. El propósito de la Comisión constitucional fue establecer lo que pudiera denominarse una separación imperfecta a través de la superación de la confesionalidad sustancial -inspiración auténtica de las instituciones en la doctrina católica-, aunque modulada por la renovación del vínculo económico. En tal sentido, el artículo 21 vino a consagrar una relación entre el Estado y la Iglesia católica de natu- 
raleza puramente económica o, como señalara Montero Ríos en los debates constituyentes-, de "simple estipendio, de jornal" 25 . Una causa histórica, la desamortización, tuvo que ser atendida, sin que ello implicara la existencia de un sistema general de relaciones privilegiadas entre la Iglesia católica y el Estado $^{26}$.

La corriente intelectual impulsora de un nuevo enfoque ahí estaba. El camino hacia el laicismo se allanó en 1869 . Y cuando se dieron todas las circunstancias para el primer intento, dentro de nuestra historia constitucional, en favor de una Constitución democrática (masculina) con plena definición y limitación de todos los poderes del Estado, se plasmó esa otra actitud en materia de relaciones Estado-Iglesia. Recuérdese lo dispuesto en los artículos 34, 35 y 36 del Proyecto constitucional de 1873: libertad de cultos, separación entre la Iglesia y el Estado y prohibición a Estado federal, regiones y municipios de subvencionar ningún culto.

La Constitución de 1931, siguiendo las huellas del Proyecto constitucional de 1873, estableció la total separación entre el Estado y cualquier Iglesia. La religión es un asunto exclusivamente personal que debe quedar relegado al ámbito de la conciencia, sin que haya de ser tenida en cuenta para la ordenación de la sociedad. Como afirmara Azaña en las Constituyentes, el auténtico problema religioso no puede exceder de los límites de la conciencia. Y ante el sentimiento religioso, la creencia, el Estado debe mantenerse alejado y neutral; esto es, tiene que ser aconfesional (art. 3). Pero en ella se incluyeron también varios preceptos abiertamente hostiles contra la Iglesia católica (arts. 26 y 27). Quienes durante siglos sufrieron la intransigencia, se contagiaron de ella. Como alertaron Ortega y Marañón, la actitud de los grupos mayoritarios obedeció más al típico trágala que a una conducta acorde con el talante democrático de la Constitución de 1931. Un error histórico.

\section{PASADO Y FUTURO}

El constituyente español de 1978 quiso, finalmente, articular un modelo de relación entre el Estado y las Iglesias fundado en la libertad religiosa y en la aconfesionalidad estatal, sin que ello implicase hostilidad frente al hecho social religioso. Quiso expresamente desterrar la confesionalidad católica, pero sin los excesos laicistas de 1931. No existe una religión oficial, a diferencia de lo sucedido durante la mayor parte de nuestra historia constitucional desde 1812, pero sí la obligación del Estado de cooperar con la Iglesia católica y el resto de confesiones a fin de promover el ejercicio real y efectivo de la libertad religiosa individual.

${ }^{25}$ Diario de Sesiones, 14 de abril de 1869, pp. 1046-1047.

${ }^{26}$ Abraham Barrero Ortega, La libertad religiosa en España, Centro de Estudios Políticos y Constitucionales, Madrid, 2006, pp. 54-59. 
Si el origen histórico de la libertad religiosa está en la tradición liberal, que la concibió como una libertad negativa o un derecho de defensa, como un derecho a la no injerencia, en el siglo XX esta concepción se ha visto confrontada con la tradición democrática que cristaliza constitucionalmente en el paso del Estado liberal al Estado social. La Constitución añadirá a su tradicional función de garantía de los derechos individuales una nueva función, la promocional, a través de la cual los poderes públicos intervienen positivamente para crear las condiciones y remover los obstáculos que dificulten o impidan la libertad (art. 9.2 CE). La libertad religiosa no es una excepción y, junto a la no interferencia, incorpora también técnicas positivas de promoción como las relaciones de cooperación. En este contexto, la formulación expresa del principio de cooperación en el artículo 16.3 CE implica el reconocimiento de una vertiente positiva de la libertad religiosa y, en última instancia, la conveniencia de que los poderes públicos colaboren con las confesiones para la realización de la libertad individual. Los pactos o acuerdos de cooperación (así, art. 7.1 de la Ley Orgánica 7/1980, de Libertad Religiosa), aparte de su naturaleza jurídica específica, responden a la idea de concertar con cada confesión un estatuto que adapte el marco jurídico general de la libertad religiosa a sus particularidades. Se trata, sea como fuere, de una cooperación instrumental; se coopera para algo y ese algo no puede sino el ejercicio individual o colectivo de la libertad religiosa. Se quiere facilitar el disfrute de la libertad de religión.

El reconocimiento de esta vertiente positiva o promocional de la libertad religiosa exige, por consiguiente, matizar el dogma de la no interferencia, incompetencia o neutralidad del Estado en sede de conciencia y religión. La laicidad ya no puede interpretarse hasta el extremo de imposibilitar la cooperación, aunque conserva la función de límite del principio de cooperación pues éste no puede llevar al Estado a valorar positivamente lo religioso en cuanto tal y ni mucho menos a privilegiar -sin causa objetiva y razonable- a una concreta confesión.

A partir de esta evolución y cambio de perspectiva en lo que respecta a la no interferencia, cabría sistematizar las líneas de actuación del Estado en relación con el fenómeno religioso en cuatro apartados ${ }^{27}$ : a) las situaciones de mero dejar hacer, sin intervención alguna, en el sentido más clásico (p.e., no interferir en los actos de culto en los templos); b) las respuestas positivas institucionales para crear una red que permita proteger lo anterior (p.e., tutela penal de la libertad religiosa); c) el tradicional campo del Derecho administrativo en la protección del orden público -entendido en un sentido cívico-, lo que se viene denominando la policía administrativa (p.e., exigencias urbanísticas); y d) un cierto espacio para las prestaciones que debe asumir el poder público (p.e., ayudas dinerarias o exenciones tributarias o reconocimiento de efectos civiles al matrimonio religioso).

${ }^{27}$ Lorenzo Martín-Retortillo Baquer, "El marco normativo de la libertad religiosa", Revista de Administración Pública, 148, 1999, pp. 7-40. 
¿Ha dejado España de ser católica? ¿Sigue comprometiendo la cuestión religiosa la firmeza de nuestro Estado constitucional? Sin negar los problemas que se han ido suscitando y seguirán suscitándose con ocasión de la puesta en práctica de los principios contenidos en el artículo 16 de nuestra Constitución, está claro que la libertad religiosa y la relación Estado-Iglesia católica ha dejado de ser un problema para la convivencia democrática. Es la lógica de los derechos fundamentales. El Estado constitucional español no puede quedar comprometido por la relación privilegiada de los poderes públicos con una concreta confesión religiosa. La religión de la España democrática ni es ni será la católica.

Sin embargo, es igualmente evidente que algunas de las zonas de penumbra de nuestro actual sistema de relaciones Estado-Iglesias se comprenden y enjuician con mayor lucidez si se atiende al dato histórico. La desconfesionalización de nuestro Estado Constitucional aún está en marcha, lo cual provoca disfunciones tangibles. El retraso histórico de los países latinos en el reconocimiento de la libertad religiosa y la laicidad estatal es significativo. No por casualidad, Italia y España sancionan en sus Constituciones la cooperación junto a la laicidad, lo que, en más de un sentido, puede contemplarse como un intento de adaptar fórmulas confesionales a la nueva realidad democrática en la que la laicidad es un activo irrenunciable ${ }^{28}$.

Pero lo cierto es que, en nuestro país, no se ha progresado lo suficiente en dimensiones igualitarias de la libertad religiosa, sino que, por el contrario, se han ahondado las diferencias a favor de las confesiones más poderosas (con acuerdo de cooperación) y, principalmente, de la Iglesia católica. La igualdad y laicidad exigen, en buena lógica, que el Estado ofrezca a todas las convicciones, creencias y confesiones una misma estructura jurídica a la que hacer centro de imputación de derechos, obligaciones y beneficios. La configuración de esta estructura jurídica común supone el reconocimiento constitucional de la igualdad de las mismas ante la ley. Esta igualdad es, sin duda, compatible con la diversidad de convicciones y creencias y con la organización y el régimen de cada una de ellas, porque no hay que confundir igualdad con uniformidad. El reconocimiento, si se quiere a través del acuerdo de cooperación, de las peculiaridades de los sujetos colectivos de la libertad religiosa no quiebra la igualdad. Pero la mejora de nuestro modelo de protección de la libertad religiosa pasa, en mi opinión, por privilegiar esa estructura jurídica común frente a las variantes convencionales referidas a lo religioso. Desafío de futuro de cara a una eventual reforma del marco normativo de la libertad religiosa ${ }^{29}$.

${ }^{28}$ María Holgado González, "La dimensión social de la libertad religiosa", en Abraham Barrero Ortega y Manuel Terol Becerra, M.: La libertad religiosa en el Estado social, Tirant Lo Blanch, Valencia, 2009, pp. 211-220.

${ }^{29}$ Lorenzo Martín-Retortillo Baquer, op. cit., pp. 7-40. Asimismo, Abraham Barrero Ortega, "Apuntes críticos al sistema español de acuerdos de cooperación”, Cuadernos de Derecho Público, 33, 2008, pp. 123-136. 